\title{
A importância das notas em dicionário terminológico português/italiano
}

\author{
Rosemary Irene Castañeda Zanette*
}

\begin{abstract}
Each terminological/terminographic work involving two languages, according to its objectives and user group, favors one or another part of the dictionary entry, mainly the equivalent or the definition. The cross-references also has a important rule in the construction of the product, to help the dictionary user to elucidate the information that seeks or expanding his knowledge, when he checks other suggested terms. There is also the option to include notes, linguistic or encyclopedic, that can improve the product very much, bringing curiositys or different kind of data, not included in the definition. Accordingly, this paper intends to present some discussion about the presence and the contribution of this last element, in the doctoral work Portuguese/italian bilingual terminology dictionary of cultural and natural heritage subfields.
\end{abstract}

Keywords: Terminological dictionary - Italian - note.

Resumo: Cada trabalho terminológico/terminográfico que envolva duas línguas, de acordo com seus objetivos e público-alvo, privilegia uma ou outra parte do enunciado lexicográfico, principalmente a forma equivalente ou a definição. 0 sistema de remissivas também tem papel fundamental na composição da obra, ajudando o consulente a tornar ainda mais clara a informação sobre o que procura ou ainda ampliando seu conhecimento, quando ele verifica outros termos sugeridos. Há também a opção de se incluir notas, linguísticas ou enciclopédicas, que podem enriquecer muito o trabalho, trazendo curiosidades ou dados de diverso tipo, não contemplados pela definição. Assim, este trabalho pretende apresentar algumas discussões sobre a presença e a contribuição deste último elemento, no trabalho de doutorado Dicionário terminológico bilíngue português/italiano das subáreas do Patrimônio Cultural e do Patrimônio Natural.

Palavras-chave: Dicionário terminológico - Língua italiana - nota

"Universidade Estadual do Oeste do Paraná. Email: rczanette@hotmail.com. 
Zanette, R. I.C. - A importância das notas em dicionário terminológico português/italiano

\section{Introdução}

O foco deste artigo é o dicionário elaborado na tese de doutorado intitulada Dicionário terminológico bilíngue português/italiano das subáreas do Patrimônio Cultural e do Patrimônio Natural, sob orientação da Profa. Dra. Maria Aparecida Barbosa, do Departamento de Linguística, da Universidade de São Paulo. O trabalho enquadra-se na linha de pesquisa "Análise do léxico". Seu tema foi escolhido devido à importância da valorização dos bens culturais e dos bens naturais, e também devido à ausência de obras terminológicas que tratassem do assunto, tanto no mercado editorial brasileiro, quanto no italiano. Diante disso, a obra está com vistas à publicação.

Como dicionário terminológico bilíngue unidirecional, seu objetivo é esclarecer para o consulente o significado do termo desconhecido na língua estrangeira. Para atingir esse fim, foi preciso combinar decisões em relação à macroestrutura e à microestrutura, a fim de tornar o produto final bastante eficaz para aquele que o utiliza. No primeiro caso, não há muita variabilidade: a organização pode ser em ordem sistemática, de acordo com o mapa conceitual da área em questão; em ordem alfabética; ou, por fim, de modo misto. No segundo caso, há vários elementos envolvidos. Para uma melhor estruturação, decidiu-se utilizar, como parâmetro, o modelo de microestrutura proposto por BARBOSA:

Artigo $=[+$ Entrada (vocábulo) + Enunciado lexicográfico $(+$ Par . Inform. I (pronúncia, abreviatura, categoria, gênero, número, etimologia, área, domínio, subdomínio etc.), + Par. Definicional (acepção específica da área científica/tecnológica ou de um falar especializado), + Par. Pragmático (exemplo de emprego específico daquela área), +/- Par. Inform. 2 (freqüência, normalização, banalização/vulgarização/popularização, etc.) ... +/- Par. Inform. n), + Remissivas (relativas ao Universo de Discurso em questão)] (BARBosA 2001: 39). 
Zanette, R. I.C. - A importância das notas em dicionário terminológico português/italiano

Para aplicá-lo ao Dicionário terminológico bilíngue português/italiano das subáreas do Patrimônio Cultural e do Patrimônio Natural foi necessário fazer algumas adequações. Obteve-se, assim, a seguinte organização:

\footnotetext{
+ entrada em português + paradigma informacional (+ categoria gramatical, + gênero + número);

+ forma equivalente em língua italiana;

+ paradigma definicional (definição redigida em língua portuguesa);

+ paradigma pragmático (abonação em língua portuguesa);

+/- remissivas (para as formas sinonímicas e variantes preferenciais como siglas e acrônimos, além dos hiperônimos, hipônimos, coipônimos);

+/- notas de caráter linguístico e/ou enciclopédico (ZANETTE 2010: 103).
}

Para atingir seus objetivos, a obra necessita da integração de todos esses elementos, embora alguns deles se sobressaiam, como a forma equivalente e a definição. Ambos esclarecem ao consulente o conceito, seja por meio do termo correspondente na língua estrangeira, seja pela descrição pormenorizada do conteúdo semântico-conceptual. Em relação aos outros elementos do enunciado lexicográfico, este trabalho pretende trazer algumas considerações sobre a presença e a contribuição das notas enciclopédicas no referido dicionário terminológico.

\section{A tipologia e o lugar das informações em diferentes dicionários}

A definição é um dos principais elementos nos dicionários comuns, nos dicionários enciclopédicos e nos dicionários especializados. Porém, o tipo de obra determina uma tipologia de definições. KRIEGER e FINATTO apresentam a seguinte proposta: 
Zanette, R. I.C. - A importância das notas em dicionário terminológico português/italiano

a) definições lexicográficas caracterizam-se pela predominância de informações linguísticas, tratando mais de "palavras";

b) definições enciclopédicas se ocupam mais de referências e de descrição de "coisas";

c) definições terminológicas trazem predominantemente conhecimentos formais sobre "coisas" ou "fenômenos"

(KRIEGER e FINATTO 2004: 167).

No primeiro caso, a obra traz uma série de acepções de uma mesma palavra, nos mais variados contextos. No segundo, além da definição, há informações de caráter vário sobre a entrada e, algumas vezes, ilustrações. No terceiro, a cada entrada corresponde apenas uma definição, já que se trata de contexto específico, a qual é composta por semas específicos da linguagem de especialidade em questão. Para deixar mais claras essas diferenças, buscou-se a entrada chafariz nas três diferentes obras.

Em um dicionário geral, como o DicıONÁRIO HouAISS 1.0 (2001), há três acepções possíveis:

chafariz s.m. (1392 cf. IVPM) 1 hidrol extremidade de um conduto de água, próprio para abastecimento público 2 arq hidrol fonte com uma ou mais bicas por onde corre água, na maioria das vezes fazendo parte de um conjunto arquitetônico 3 p.ana. joc. indivíduo que chora constante e abundantemente etim ár. sihrídj 'cisterna, tanque', segundo JM pela forma vulg. sahrídj; f.hist. 1392 çafarege, 1392 caffarege, 1393 chafariz

(DICIONÁRIO HOUAISS 1.0: 2001)

Além disso, há a informação gramatical (substantivo masculino), a datação e a etimologia.

Em relação às enciclopédias, atualmente as versões on-line acabaram tomando o lugar das versões impressas. No entanto, as bibliotecas públicas, bem como as bibliotecas universitárias, ainda conservam esses exemplares. No quarto volume da GRANDE ENCICLOPÉDIA DELTA LAROUSSE, encontrou-se: 
Zanette, R. I.C. - A importância das notas em dicionário

terminológico português/italiano

chafariz. s.m. Fonte de uma ou mais bicas por onde corre a água: bebedouro público. ( 0 chafariz é a extremidade de um conduto de água, antigamente construído para abastecimento público, hoje utilizado apenas com função ornamental em praças, jardins etc. Pode consistir somente num muro dotado de um ou vários canos dos quais a água jorra, indo depositar-se num tanque onde serve para uso dos animais; outras vezes apresenta-se como construção arquitetônica, frequentemente de aspecto rochoso, ornado de figuras mitológicas ou de animais relacionados com a água (Netuno, peixes, tartarugas etc.). $\mathrm{Na}$ Europa são particularmente famosos os belos e monumentais chafarizes de Roma; em Paris é célebre a fonte da avenue de l'Observatoire, obra de Carpeaux; Lisboa teve seus chafarizes multiplicados sobretudo no período pombalino. No Brasil há chafarizes que provêm do período colonial, como os do Rio de Janeiro e de Ouro Preto) (GRANDE ENCICLOPÉDIA DELTA LAROUSSE 1974: vol. IV, 1528).

Além da informação gramatical e da definição, há informações sobre os diversos usos do chafariz com o advento da urbanização das cidades, além de suas possíveis formas. Os dados sobre alguns deles são apenas curiosidades, portanto não são imprescindíveis para a compreensão do significado. $\mathrm{Na}$ página em que se encontra a entrada em questão, há cinco fotos ilustrando diversos exemplares brasileiros.

Por fim, no Dicionário terminológico bilíngue português/italiano das subáreas do Patrimônio Cultural e do Patrimônio Natural, chafariz é assim apresentado:

chafariz s.m.

fontana

Equipamento urbano, extremidade de um conduto de água, com várias saídas, geralmente decorado com esculturas, que tem por função o abastecimento de água.

" $<$ Chafariz> à Rua do Riachuelo (Rio de Janeiro, RJ)

Descrição: Segundo Magalhães Corrêa, em seu livro 'Terra Carioca Fontes e <Chafarizes>, pelo ano de 1817 a cidade sofreu de falta d'água em conseqüência da seca. As águas encontradas nas nascentes dos Morros de Mata-Cavalos, Desterro e Santa Teresa estavam localizadas em terras particulares. Por iniciativa do Desembargador do Paço e Intendente Geral da Polícia Paulo Fernandes Viana, foi construído no mesmo ano o <chafariz> na antiga rua de Mata-Cavalos, hoje Riachuelo, após conseguir a doação do terreno do Tenente Coronel Cláudio José Pereira da Silva. Segundo o arquiteto Augusto 
Zanette, R. I.C. - A importância das notas em dicionário terminológico português/italiano

Carlos da Silva Telles, as dimensões do <Chafariz $>$ foram reduzidas pelas várias reformas, 'que the conservaram, no entanto, em muita boa cantaria, o tanque, as pilastras e a cartela com os dizeres: - O Rei por bem de seu povo M.F.E.O (mandado fazer e oferecido) pela Polícia -1817 '”.

(http://www.iphan.gov.br/ans/inicial.htm)

Sin. fonte

Cf. equipamento urbano

Nota: Com o desenvolvimento das cidades e de nova rede de abastecimento de água, o chafariz deixou sua antiga função e passou a ser reconhecido e utilizado apenas como ornamento.

(ZANETTE 2010: 124)

Observa-se também que há a informação gramatical. Uma característica marcante desse tipo de obra está na acepção única, ou seja, para um significante há apenas um significado, o que reforçaria o ideal de univocidade das linguagens de especialidade. Outra questão é a presença do sema equipamento urbano, utilizado pela subárea do Patrimônio Cultural, o qual não aparece nas obras anteriores.

Tendo em vista os três tipos de obras, o elemento que figura em todas elas é a definição, no caso de uma ou de mais acepções. A informação gramatical também está sempre presente. $\mathrm{Na}$ obra lexicográfica, o importante é trazer uma lista exaustiva das diversas acepções de chafariz. A obra enciclopédica "traz informações pormenorizadas tanto sobre palavras quanto sobre conhecimento de coisas" (KRIEGER e FinatTo 2004: 169). Na última obra, a definição única refere-se a uma determinada linguagem de especialidade. Procura ser concisa e bastante precisa. Em sua nota, encontram-se informações semelhantes às da obra enciclopédica. Tal fato ocorre no contexto específico deste trabalho. 
Zanette, R. I.C. - A importância das notas em dicionário terminológico português/italiano

\section{As notas enciclopédicas no dicionário analisado}

O Dicionário terminológico bilíngue português/italiano das subáreas do Patrimônio Cultural e do Patrimônio Natural possui um total de 83 termos em seu mapa conceitual. Deste total, 36 termos, ou seja, pouco menos de 50\%, contam com a nota enciclopédica em sua microestrutura. Ambas as subáreas dividem igualmente a quantidade de notas, 18 para cada. Sobre a tipologia das informações contidas nas notas, a escolha foi realizada de acordo com as características de cada termo.

Os principais termos da referida obra terminológica são Patrimônio Cultural e Patrimônio Natural. São acompanhados por notas com as mesmas informações, ou seja:

A Convenção para a Proteção do Patrimônio Mundial, Cultural e Natural da UNESCO de 16 de novembro de 1972 estabelece alguns conceitos e normas. Unifica, desse modo, as práticas para a proteção do Patrimônio Cultural e do Patrimônio Natural, as quais devem ser realizadas por todos os estados-membros da organização (ZANETTE 2010: 172).

Há a referência ao documento da Organização das Nações Unidas para a Educação, a Ciência e a Cultura (UNESCO) que normatiza as ações que envolvem a identificação e preservação dos bens das mencionadas subáreas.

Com relação às demais notas, como as subáreas têm características diferentes, os próximos comentários tratarão de cada uma delas em separado.

Os conceitos dos termos do Patrimônio Cultural dessa obra terminológica referem-se ao momento do tombamento, ou seja, é considerado o motivo pelo qual o bem recebeu essa proteção institucional. É preciso fazer esta consideração, pois assim como as palavras da língua geral, os termos também podem ter um período de vida, podem representar conceitos distintos com o passar do tempo, ou então podem adquirir ou 
Zanette, R. I.C. - A importância das notas em dicionário terminológico português/italiano

perder certos traços conceituais em suas definições. Diante disso, algumas notas trazem alguns dados sobre a história do bem representado linguisticamente pelo conceito. Muitos sobrados foram tombados por serem edificações de um ou mais pavimentos, destinados a uso residencial. 0 que a nota traz como complemento é que, além desse uso, o primeiro pavimento de muitos deles era utilizado para fins comerciais. É o que acontece, por exemplo, com o Sobrado, à Rua Marechal Deodoro, 12, em São João Del Rei, Minas Gerais (Arquivo Noronha Santos). Outro caso semelhante é o do paço municipal. Atualmente ele sedia os governos municipais e, por isso, foi tombado. A nota resgata um antigo uso da edificação, em que ela era utilizada como casa de câmara e cadeia, em que o piso inferior era destinado à tutela dos criminosos e o piso superior às autoridades. É o caso do Paço Municipal de Jaguaribe, Bahia. Há outros casos, em que o sentido é o inverso. O bem foi tombado por um antigo uso, mas atualmente é reconhecido por um novo uso. 0 próprio chafariz foi tombado pela sua função de abastecimento de água. A nota na obra terminológica, bem como as informações trazidas pela obra enciclopédica vista anteriormente, apresentam uma visão mais atual do bem. Hoje os chafarizes são reconhecidos apenas como ornamento. A urbanização das cidades aprimorou seu sistema de distribuição de água, fazendo com que esse bem perdesse essa sua função e, que, consequentemente, seu conceito perdesse também alguns traços conceituais. 0 termo fazenda também merece destaque. Sua proteção deu-se sempre devido à sua utilização para agricultura e pecuária, como em relação à Fazenda do Pinhal, em São Carlos, São Paulo. O conceito ampliou-se. Hoje esse conjunto de edificações rurais pode ser utilizado para outras atividades como a silvicultura, a piscicultura, entre outras, o que esclarece a nota.

Em alguns casos em que há a variação diatópica, como em centro histórico e centro storico, a nota procura fornecer algum detalhe que diferencia o bem nos dois países: "Muitas cidades italianas medievais têm seu centro histórico claramente delimitado pelos muros, os quais serviam para a 
Zanette, R. I.C. - A importância das notas em dicionário terminológico português/italiano

sua defesa. É o caso do centro histórico de Roma" (Zanette 2010: 123). Já no Brasil, não existiram tais muros. Já sítio arqueológico e area archeologica são definidos como: "bem arqueológico em que se encontram vestígios da vida de povos antigos que passaram ou viveram em determinada região" (ZANETTE 2010: 187). Porém, a nota explica que a diferença entre ambos está no tipo de povos que passaram pelas regiões, bem como nos diferentes períodos em que isso aconteceu:

No Brasil, os vestígios são dos paleoameríndios e dos escravos fugidos das fazendas durante o período do Brasil Colônia. $\mathrm{Na}$ Itália os vestígios não são dos paleoameríndios, mas de outros povos, do povo formador do Império Romano e de outros povos bárbaros que passaram pela Itália, desde os mais remotos períodos antes de Cristo (ZANETTE 2010: 187).

Outras notas que acompanham os termos do Patrimônio Cultural demonstram como diversas edificações, como algumas públicas e privadas, hoje sediam órgãos de governo, repartições públicas ou instituições culturais. Este é o caso do paço imperial, localizado na cidade do Rio de Janeiro, que atualmente sedia um centro cultural vinculado ao Instituto do Patrimônio Histórico e Artístico Nacional (IPHAN). Há também as casas que tem por função servir de residência a personalidades importantes, como a Casa de Graciliano Ramos, em Palmeira dos Índios, Bahia, que atualmente sedia um museu e uma biblioteca com o acervo do escritor.

Em relação aos termos do Patrimônio Natural, eles baseiam-se no conceito de unidade de conservação, ou seja:

área demarcada, com seus recursos ambientais e águas jurisdicionais, sob regime especial de administração, legalmente instituída pelo Poder Público, em nível federal, estadual ou municipal, que objetiva conservar e preservar suas características naturais de valor relevante (ZANETTE 2010: 194). 
Zanette, R. I.C. - A importância das notas em dicionário terminológico português/italiano

A subárea segue leis nacionais, como decretos, códigos, ou internacionais, como algumas convenções, entre outros documentos oficiais.

Em relação às notas, a tipologia de informações que elas trazem também é vária. Algumas notas também apresentam as diferenças entre a unidade de conservação no Brasil e na Itália, tanto em uma entrada que possui a forma equivalente, como em uma entrada que não a possui. No primeiro caso, a reserva biológica e o equivalente, riserva naturale, contam com a informação que no país europeu a posse e domínio podem ser do Estado ou de uma de suas vinte regiões, já que a divisão administrativa nos dois países é diferente. No segundo caso, há a unidade de conservação do SNUC. O termo indica: "unidade de conservação do sistema instituído pelo Governo Federal brasileiro, conhecido como Sistema Nacional das Unidades de Conservação da Natureza, que gerencia a criação, a implantação e a gestão desse tipo de unidade" (ZANETTE 2010: 199). Na nota encontra-se a informação sobre o sistema utilizado na Itália:

$\mathrm{Na}$ Itália há um sistema semelhante, que institui, pela Legge 6 dicembre 1991, n. 394, as Aree Naturali Protette. As categorias são: parco nazionale, parco naturale regionale o interregionale, riserva naturale, zona umida di interesse Internazionale, altre aree naturali protette e aree di riperimento terrestri e marine (ZANETTE 2010: 199).

São dois sistemas que partem basicamente do mesmo princípio de preservar áreas e bens naturais, mas mantendo suas especificidades.

Em relação a parque estadual e parco naturale regionale, a questão que os difere também se relaciona à divisão administrativa dos territórios. Desse modo, a nota coloca que na Itália, o parque pode estar localizado tanto em uma única região, como pode ocupar partes de regiões limítrofes.

A quantidade de unidades de conservação existentes nos dois países também compõe as notas, principalmente das unidades de conservação de interesse internacional, geridas pela UNESCO. Tendo sempre como ponto de partida a realidade brasileira, as notas apontam que em seu território há um 
Zanette, R. I.C. - A importância das notas em dicionário terminológico português/italiano

único geopark, cinco reservas da biosfera, 17 sítios do patrimônio mundial e oito sítios ramsar. Na Itália a quantidade respectiva é três, oito, quarenta e quatro e cinquenta. É claro que a impressão causada pelos números deve ser relativizada, pois há vários fatores que podem influenciar nessa contabilização, como as diferentes características físicas dos dois territórios, a dimensão de cada um deles, e, até mesmo, o empenho de cada país em cumprir as diretrizes estabelecidas pela organização internacional, bem como sua relação com a mesma.

Por fim, algumas notas realmente apresentam informações muito distintas, dependendo das especificidades da unidade de conservação a que se referem. É o caso de reserva de desenvolvimento sustentável. A reserva, apesar de ter sido instituída por lei federal, ou seja, pode ser legalizada em qualquer parte do território brasileiro, concentra-se na região norte. É essa informação contida na nota. Já na microestrutura de reserva florestal legal, as informações adicionais falam da porcentagem que a reserva deve ocupar dentro da propriedade rural em que ela se encontra. Deve ocupar $20 \%$ em grande parte do país, 35\% dentro do bioma cerrado, que por sua vez está dentro da Amazônia Legal, e, por fim, 80\% na própria Amazônia Legal, dados extraídos da Lei o 4.771, de 15 de novembro de 1965, ou seja, o Código Florestal.

\section{Considerações finais}

Cabe ao terminólogo tomar muitas decisões quanto à composição e à organização de sua obra. São questões de ordem externa, como objetivos e público-alvo, bem como questões de ordem interna, como seleção dos termos, definição da macroestrutura e da microestrutura. A combinação de todos esses elementos, resultado de escolhas bastante refletidas, dará corpo à obra 
Zanette, R. I.C. - A importância das notas em dicionário terminológico português/italiano

que se pretende construir. O dicionário elaborado na tese Dicionário terminológico bilíngue das subáreas do Patrimônio Cultural e do Patrimônio Natural é uma obra de definição em língua portuguesa, com formas equivalentes em língua italiana. Além disso, seu enunciado lexicográfico é composto pelas abonações, pelo sistema de remissivas e pelas notas, o que torna a obra bastante completa. Como mencionado, o consulente interessa-se sobretudo pelo paradigma definicional ou pelas formas equivalentes. No entanto, as notas, ferramenta opcional nesse tipo de obra, vêm complementar a microestrutura, principalmente para aquele que quer se aprofundar na temática em questão. Diante dos números expostos, percebe-se que a nota não é um elemento que deve estar acompanhando necessariamente todos os termos e também não há uma definição sobre a tipologia das informações que deve conter. 0 corpus documental com que se trabalhou, ou seja, a legislação brasileira e a italiana, além de outros textos especializados disponíveis na internet, é que forneceu os dados que foram incluídos nas notas. Numa pesquisa com outro tipo de corpus, o resultado poderia ser diverso. Tendo em vista os exemplos apresentados, pode-se concluir que este elemento do enunciado lexicográfico, nesse específico caso, reforça as semelhanças e diferenças entre o tratamento dado às subáreas do Patrimônio Cultural e do Patrimônio Natural nos dois países. Vem dessa forma, reafirmar o conceito para o consulente. 
Zanette, R. I.C. - A importância das notas em dicionário terminológico português/italiano

\section{Referências bibliográficas}

BARBOSA, M. A. Dicionário, vocabulário, glossário. In: ALVES, leda Maria (org.). Cadernos de Terminologia n. 1: a constituição da normalização terminológica. 2. ed. São Paulo: Humanitas/FFLCH, 2001.

BRASIL. Lei $n^{\circ} 4.771$, de 15 de novembro de 1965. Institui o novo Código Florestal. Diário Oficial da União, Brasília, 1965. Disponível em: <http://www.planalto.gov.br/ccivil_03/Leis/L4771.htm>. (10/05/11).

Dicionário HoualsS 1.0. Rio de Janeiro: Editora Objetiva, 2001.

Grande enciclopédia Dela LARousSe. Ed. rev. e atual. Rio de Janeiro: Editora Delta S.A., 1974.

KRIEger, M. da G.; FinatTo, M. J. B. Introdução à terminologia: teoria \& prática. São Paulo: Contexto, 2004.

ZANETTE, R. I. C. Z. Dicionário terminológico bilíngue das subáreas do Patrimônio Cultural e do Patrimônio Natural. 2010. 249 p. Tese (Doutorado) - Faculdade de Filosofia, Letras e Ciências Humanas, São Paulo, 2010. 